\title{
Currency Crises and Purchasing Power Parity in the Asian Countries: Evidence Based on Second-Generation Panel Unit-Root Tests
}

\author{
Siew-Voon Soon ${ }^{\mathrm{a}}$ \\ Universiti Putra Malaysia \\ Ahmad Zubaidi Baharumshah ${ }^{\mathrm{b}}$ \\ Universiti Putra Malaysia \\ Nurul Sima Md. Shariff \\ Universiti Sains Islam Malaysia \\ Saifuzzaman Ibrahim ${ }^{d}$ \\ Universiti Putra Malaysia
}

\begin{abstract}
This study applies a second-generation panel unit-root tests to determine the stochastic properties of real exchange rates for 14 Asian countries. Based on three popular alternative definitions of a currency crisis, we identify the several important currency crisis episodes in the region. The purchasing power parity (PPP) hypothesis was overwhelmingly supported after accommodating these heterogeneous noisy and unstable observations. Our panel unit-root test that controls for cross-sectional dependence and is robust to structural breaks confirms that the crisis in all the countries fits well with the second-generation models of currency crisis, that is, the root cause of the currency crises may not lie in economic fundamentals. PPP relation emerges when breaks and cross country dependency has been taken into account for these 14 countries.
\end{abstract}

Keywords: Asian, cross-sectional dependency, real exchange rate, second-generation models

JEL classification: C23, E30, F31

\section{Introduction}

Generally, a currency crisis is defined as a speculative attack on the foreign exchange value of a currency that either results in a sharp depreciation or forces the authorities to defend the currency by selling foreign exchange reserves or raising domestic interest

a Department of Economics, Faculty of Economics and Management, Universiti Putra Malaysia, 43400 UPM Serdang Selangor, Malaysia. Email: s_siewvoon@upm.edu.my, sv_soon2001@yahoo.com

b Financial Economics Research Centre, Faculty of Economics and Management, Universiti Putra Malaysia, 43400 UPM Serdang Selangor, Malaysia. Email: zubaidi@upm.edu.my, baharumshah@yahoo.com (Corresponding author). The author is also attached to the Department of Economics, Universiti Putra Malaysia.

c Faculty of Science and Technology, Universiti Sains Islam Malaysia, Bandar Baru Nilai 71800 Nilai, Malaysia. Email: nurulsima@usim.edu.my

d Department of Economics, Faculty of Economics and Management, Universiti Putra Malaysia, 43400 UPM Serdang Selangor, Malaysia. Email: saifuzzaman@upm.edu.my

* The authors gratefully acknowledge financial support from the Malaysian Ministry of Science, Technology and Innovation (MOSTI) [Grant no: 06-01-04-SF1248] and UPM [GP-IPB/2014/9440900]. The authors are grateful to an anonymous referee and the editor for constructive comments and encouragements. The authors alone are responsible for any errors that may remain. 
rates. The currency crises in Latin America (1981-1982), the European exchange rate mechanism (1992), Mexico (1994-1995), and Asia (1997-1998) have drawn considerable attention, devoted mainly to the major causes and consequences of these events. These crises have had a broader impact on the global financial system and are often associated with large economic and social costs. The Asian financial crisis (AFC), which is the main focus of our study, also offers several explanations for the crisis and can be broadly classified into two main groups - labelled as 'first-' and 'secondgeneration' models. The first group of scholars attributes the crisis to the deterioration in fundamental imbalances as explained by the first-generation models (FGMs) of the currency crisis (Corsetti, Pesenti, \& Roubini, 1999; Dooley, 1999, just to name two). Popularised by Krugman (1979), the FGMs emphasise that the crisis erupted because of mismatch between fiscal and monetary policies that eventually led to a continuous deterioration in the economic fundamentals. A speculative attack on a fixed exchange rate regime begins when investors foresee that a government, which runs an excessive deficit, has insufficient liquid assets to support its currency at the fixed rate. ${ }^{1}$

Another favoured view in the currency crisis literature, however, claims that there was nothing inherently wrong with the economic fundamentals during that period, although it acknowledges the worsening macroeconomic performance in some affected countries in the mid-1990s (Radelet \& Sachs, 1998). This later group of scholars puts forth the notion that the second-generation models (SGMs) of currency crises had better explain the Asian 1997 crisis. Introduced by Obstfeld (1986), advocates of the SGMs emphasise that the currency crises are possible, even without a sizable deterioration in the fundamentals of the economy. Accordingly, a minor disturbance in the economy can cause a sudden loss in domestic and international investors' confidence. These models predict that doubts among investors on whether the government is willing to continue supporting its fixed exchange rate regime lead to multiple equilibria. Investors attack the currency, as they expect others to do the same during the period of incorrect policy choices. In fact, all models of SGMs emphasise on the role of multiple equilibria that arises from nonlinearities in behaviour generated by tradeoff between different policy targets like economic growth or full employment. Finding support for a long-run PPP relationship outside the crises episodes would indicate the SGMs emphasise non-fundamentals (self-fulfilling or contagion without any role for weak domestic fundamentals) during a speculative attack (Breitung \& Candelon, 2005).

The two interpretations of the crisis mentioned above are based on two different theories and thus could lead to different policy conclusions. As we know, if the currency crisis is due to FGMs - that is, the currency crisis tends to be preceded by weak economic fundamentals (e.g., excessive appreciation of the currency, depletion of foreign exchange reserves, an unsustainable current account imbalance, and a rise in unemployment) - then it should be possible to develop an early-warning system to anticipate a currency attack. However, the warning sign from a fundamentals-based

1 The FGMs rely on government debt and perceived inability of the government to control the budget as the key cause of currency crises. Excessively expansionary fiscal and monetary policies have often been blamed for a persistent loss of international reserves, which ultimately forces authorities to abandon the peg to the US dollar by either devaluing or floating the domestic currency (Fontaine, 2005). 
model is less useful if the episode is triggered by self-fulfilling expectations. Warning signs are less clear about the SGMs type of crisis since the currency crises can occur without any change in fundamentals. It should be mentioned that the FGMs and SGMs differ in terms of institutional arrangements that reduce the likelihood of crises. As mentioned in Flood and Marion (1997), the earlier models suggest that strengthening cross-country currency will stabilise exchange rates (p. 4). Breitung and Candelon (2005) based on a formal econometric work found that the experience of Mexico in 1994 fits with the prediction of the FGMs while the AFC corresponds to the SGMs. They forcefully argued that since PPP holds for Asian countries outside the crisis periods, the currency crisis of the late 1990s has no long lasting link between exchange rate and relative prices (p. 126). On the contrary, violation of PPP even when the crisis periods are removed suggests that the real exchange rates (RER) were inappropriate because of inadequate/inconsistent economic policies (Husted \& MacDonald 1999).

This study contributes to the literature by looking at how the financial crises have affected the stochastic properties of the RER, especially in reference to the Chinese renminbi and the Indian rupee. Our primary aim is to investigate the validity of the purchasing power parity (PPP) hypothesis by excluding periods of noisy and unstable observations. Breitung and Candelon (2005) use a sample period that ends in 2001. Our data span over two financial crises: the 1997-98 AFC and the 2007-09 global crises. Data during those periods are subject to (financial) bubbles, as discussed in the literature (Jiang, Bahmani-Oskooee, \& Chang, 2015; Zhou \& Kutan 2011; Baharumshah, Liew, \& Chowdhury, 2010; Baharumshah, Soon, \& Boršič, 2013; Villavicencio, 2008; BahmaniOskooee, Kutan \& Zhou, 2008; Nusair, 2001; just to name a few) and they can cause severe measurement errors. The implication is that standard unit-root tests become utterly uninformative due to the presence of outliers in the sampling period. Our methodology takes advantage of recent advances in panel econometrics and applies them to estimate the dynamic properties of the RER. Our findings that PPP is supported by the data when the two crisis periods are removed, clearly suggests that the crisis episodes do not affect permanently the link between exchange rate and relative prices. Asian currency crises fit well with the SGMs which emphasised the importance of nonfundamental factors during a crisis. In the next section, we provide a brief review of the literature. In Section 3, we discuss the research design. The empirical results, together with discussions of PPP, are explained in the penultimate section. The final section contains our conclusion.

\section{Literature Review}

In keeping with the literature, we follow the approach popularised by Breitung and Candelon (2005, B-C hereafter) to formally exclude 'extreme' observations in our samples. Following B-C, we adopt a panel unit-root test but allow for crosssectional dependence to the concepts of PPP to establish the root cause of the crisis. ${ }^{2}$

2 Failure to reject a unit-root in the logarithm of RER would imply that the deviations of PPP relation are permanent. This is described in the literature as the first PPP puzzle (Taylor, Peel, \& Sarno, 2001). 
Specifically, our interest is in determining which of the two models mentioned earlier - fundamental (FGMs) or the panic view (SGMs) - is likely to fit the currency crises characterised by drastic changes in nominal exchange rates. A breakdown in the parity condition is an indication of disequilibrium in the exchange rate that suggests a deterioration of economic fundamentals. On the other hand, a stationary (or meanreverting) RER means that the series will return to its mean value after a shock since the shock is expected to die out rapidly. ${ }^{3}$ The latter finding would be inconsistent with the fundamental view; see the argument in Husted and MacDonald (1999). The econometric explanations for the failure of PPP focus mainly on low power of the conventional unit-root tests. The new trend of the literature looks at the inability to confirm PPP as international parity condition as a statistical illusion and proposed new tests that well equip in terms of power and size. The literature has relied on longspan of samples and panel techniques to provide favourable findings. By using a panel approach for a group of developing Asian economies and a group of Organization for Economic Co-operation and Development (OECD) countries, Mishra and Sharma (2011) for example, found support for the weak form of PPP in the post-Bretton Woods era. To complement the past literature, we offer yet another explanation: the failure of the PPP hypothesis (PPP puzzle) may be due to the presence of outliers due to large swings in currency markets in the last few decades. We demonstrate that removing outliers in the sampling period could have a notable impact on the outcome of the standard unitroot tests.

Our empirical work is closely connected to B-C in terms of dating the currency crisis episode and to eliminate noise and unstable observations in the sample period under investigation, but we differ from them in two aspects. First, a larger panel is considered, and our sampling period is much broader than B-C and others to capture the most recent developments in the region. It includes the post-crisis period (2000-2009) and extends the cross-sectional sample to 14 Asian countries, including China and India. There is little research work done in these two countries where rapid transition is taking place. The 'two giants' also differ in the timing and the intensity of their economic progress. China's integration into the global economy started in the mid-1980s, while the institutional changes and policy reforms in India started much later. Both countries' share of world output has been increasing rapidly, and the Asian region has played an increasing role in global trade and finance in the past few decades. As these countries become increasingly open to trade and investments (and their growth rates converged to those of the developed countries), one would expect to find more favourable evidence of the parity condition.

Second, we extend the unit-root test to avoid the problems of misleading inference that are associated with first-generation panel methods that assume cross-sectional independence. Although panel data framework has been used in the past to deal with (low) power of the tests, it is not free from criticisms; see O'Connell (1998) and Taylor and Sarno (1998). It is well known that the RER in different countries may

3 Baharumshah, Soon and Wohar (2015) have shown that the half-life estimates of Asian currencies are less than two years with tight confidence intervals. 
be contemporaneously correlated (Pesaran, 2007). Cross sectional dependence is deemed to exist when there are strong co-movements among economic variables. As a result, studies that apply the first-generation panel unit-root test may over-reject the stationary null and maybe overly supportive of PPP. In fact, O'Connell (1998) has emphasised that the true size of the test statistic can be far greater than the normal size when the underlying data generating process is characterised by cross-section dependence. This explains why evidence based on panel data set in the past tends to be more supportive of PPP. B-C in their work decided to tackle the issue by splitting the sample according to Asian and South and Latin American countries. For this reason, we formally test for the presence of cross-dependence (CD hereafter) and adopt a method that is specifically designed to handle this issue in panel setting. It should be noted that the literature has acknowledged that test statistic for the CD test, like the other diagnostic tests (e.g., nonlinearities), is also affected by extreme observations (and structural breaks). As such, we apply the CD test, not on the original RER series, but on the series after extreme observations during the currency episodes are removed from the data set before conducting the panel unit-root tests to confirm the PPP hypothesis.

A large and growing body of research (e.g., Matsuki \& Sugimoto, 2013; Baharumshah et al., 2010; Nusair, 2008; Hooi \& Smyth, 2007; Zurbruegg \& Allsopp, 2004; Wu, Tsai, \& Chen, 2004; Liew, Baharumshah, \& Chong, 2004; Nusair, 2001) reveals that PPP holds in most but not all of the Asian countries when structural breaks are taken into account in the analysis. ${ }^{4}$ All of them reported a major structural change that occurs during the outbreak of the AFC. They provided sensible arguments to allow for the possibility of one or more breaks in the unit-root and cointegration tests. Narayan and Popp (2010), for example, apply an ADF-type unit root to assess the non-stationary properties of the RER for six Asian countries. They found strong evidence of PPP with panel unit-root tests with multiple breaks.

However, the above mentioned papers used dummy variable methods to account for the shifts in the RER and the number of breaks (usually unknown) was set to two at most. The use of dummies suggests low frequency data assume sharp and sudden changes. In the context of PPP in Central and Eastern European countries, Chang, Liu and Su (2012) forcefully argue that breaks in the past decades are more appropriately approximated by a smooth and gradual process such as the one proposed by Enders and Lee (2012) - a flexible Fourier function (see also Bahmani-Oskooee, Chang \& Wu, 2014; Jiang et al., 2015). Taken together, spurious rejection of the null hypothesis and hence deceptive inferences might occur with the traditional break test methods. In this paper, we take a different route by excluding currency periods which are often characterised by noisy and unstable observations. The literature also suggested that the presence of such observations in the sampling period could have a notable impact

4 Hooi and Smyth (2007) found that PPP is upheld in two thirds of the Asian countries using the dollar as the base currency. It should be mentioned that their analysis was based on the panel method with one or two breaks. Aggarwal, Montanes, \& Ponz (2000) using two-break test show that PPP holds much stronger for the yen based rates compared to other reference currencies, including the US dollar. Therefore, PPP remains a controversial and unsettled issue in the Asian countries. For a comprehensive survey of previous PPP studies, see Bahmani-Oskooee and Hegerty (2009). 
on the type of testing models and outcome of unit-root tests (Zhou \& Kutan, 2011). It should be mentioned here that the speed of adjustment to PPP tends to be faster during crisis (uncertainty) periods as proven in Baharumshah et al. (2015). Specifically, we observed that the speed of convergence vis-à-vis the dollar (as measured by the half-life estimates) is faster for the post-crisis period; see also Ozdemir and Cakan (2010) on similar issue. This is also consistent with the notion that a higher volatility of the RER is compatible with a faster adjustment speed to PPP parity. In other words, a greater volatility of shocks is related to a lower degree of persistence.

\section{Research Methodology}

Before we present the method, two points are noteworthy. First, researchers have suggested that many economic series might contain some breaks, but incorrect determination of the breaks may distort the behaviour of the statistics of any series (Montãnés, Olloqui, \& Calvo, 2005). Second, to circumvent the problem, some researchers have applied the Bai and Perron's (2003) procedure to detect multiple structural breaks and accommodate them in the analysis. However, the method has to confirm the series under investigation is an $I(0)$ process first before the procedure can be applied to test for multiple breaks. ${ }^{5}$

An RER $\left(S_{t}^{r}\right)$ series generated by an autoregressive process can be characterised as:

$$
S_{t}^{r}=\rho S_{t-1}^{r}+\mu_{t}^{\prime} \delta+\varepsilon_{t},
$$

where $S_{t}^{r}=\ln E R_{t}+\ln P_{t}^{*}-\ln P_{t}, E R_{t}$ is a bilateral exchange rate, and $P_{t}^{*}$ and $P_{t}$ denote foreign and domestic prices, respectively. $\mu_{t}^{\prime}$ is a set of exogenous regressors, such as constant or constant and trend, and $\varepsilon_{t}$ is the usual residual term assumed to have a zero mean and constant variance. To identify global as well as local events that cause the breaks and remove the unstable observations in the RER series, we built on the framework as outlined in B-C and extended their model to account for CD of the series.

A segmented mean function $m_{i, t}$ is used to estimate the sub-sample mean of $t \in\left\{p+2, \ldots, S_{i}\right\}$ and $t \in\left\{S_{i}+1, \ldots, T\right\}$, equation (1) can be written as:

$$
\Delta S_{i, t}^{r}=b_{i}\left(S_{i, t-1}^{r}-m_{i, t}\right)+c_{i} \Delta \bar{S}_{t}^{r}+d_{i} \bar{S}_{t-1}^{r *}+e_{i, t},
$$

with $b_{i}=\beta_{i}-1, \bar{S}_{t-1}^{r *}=\sum_{i=1}^{N}\left(S_{i, t-1}^{r}-m_{i, t}\right) / N$ for $t=p+3, \ldots, S_{i}, S_{i}+p+3, \ldots, T$, where $m_{i, t}$ is defined as $m_{i, t}=\left\{\begin{array}{lll}S_{i, 1}^{r} & \text { for } & t \in\left\{1, \ldots, S_{i}\right\} \\ S_{i, S+1}^{r} & \text { for } & t \in\left\{S_{i}+1, \ldots, T\right\}\end{array}, S_{i, 1}^{r}\right.$ is the series under investigation, $S_{i}$ is the break date, and $S_{i, S+1}^{r}$ is the RER when a currency crisis is detected for countries $i=1,2, \ldots, N$ at time $t=1,2, \ldots, T$. Pesaran (2007) advocated a simple procedure to handle the issue of $C D$ by estimating the factor loading. In what follows, we use the

5 Like the other break tests, one cannot consider breaks too close to the beginning or end of the sample period due to the trimming factor since there are not enough observations to identify the sub-sample parameters. 
unobserved common factor as a proxy asymptotically filtering out the $\mathrm{CD}$, and it is given as $\bar{S}_{t}^{r}=\sum_{i=1}^{N} S_{i, t}^{r} / \mathrm{N}$ by averaging the cross-section of $S_{i, t}^{r}\left(\Delta \bar{S}_{t}^{r}\right.$ when $\varepsilon_{i, t}$ is serially uncorrelated) and its lagged values $\left(\bar{S}_{t-1}^{r}\right)$; see for example, Pesaran (2004). The lag order is chosen based on standard information criteria and in our case it is the Akaike Information Criteria (AIC). Note that if the lag order is one, then the three observations after the break date are dropped for $t \in\left\{S_{i}+1, \ldots, S_{i}+p+2\right\}$, because the series do not adjust to the mean during these time periods. If we increase the lag order to two, then four observations after the break are dropped and thus the analysis will start at the fifth observation for each of the countries in the panel. According to B-C, these (extreme) observations should be dropped from the test regression using the above mentioned procedure because no mean adjustment is available for these time periods. They consider detection of successful speculative attacks as equivalent to finding structural breaks in the RER series. For more detail discussion on these, the reader may refer to the original article by B-C (2005, pp. 128-129).

To perform the new panel unit-root test, the test statistic can be expressed as: $t_{i}=\hat{b}_{i}-b_{i} / \sqrt{\operatorname{Var}\left(\hat{b}_{i}\right)}$, where $t_{i}=\left(S_{i,-1}^{r T} \bar{M} S_{i,-1}^{r}\right)^{-1}\left(S_{i,-1}^{r T} \bar{M} \Delta S_{i}^{r}\right) / \sqrt{\sigma_{i}^{2}\left(S_{i,-1}^{r T} \bar{M} S_{i,-1}^{r}\right)^{-1}} \quad$ and $\sigma_{i}^{2}=\Sigma_{t-1}^{T} \hat{e}_{i, t}^{2} /(T-4)$, with $\hat{e}_{i, t}=\Delta S_{i, t}^{r}-\Delta \hat{S}_{i, t}^{r}$, and $\bar{M}$ is defined as $\bar{M}=\mathrm{I}_{t}-\bar{H}\left(\bar{H}^{T} \bar{H}\right)^{-1} \bar{H}^{T}$ with $\bar{H}=\left(\Delta \bar{Y}_{t}, \bar{S}_{t-1}^{r *}\right) . \bar{H}$ is the combination of averages of cross-sections of the first difference of $S_{i, t}^{r}$ and the adjusted values of $\bar{S}_{t-1}^{r^{*}}$. If the test statistic is greater than simulated critical values (CVs) as discussed in section 3.1, then the RER is mean-reverting and PPP holds due to non-fundamentals and vice versa. The newly constructed test statistic is not subject to the so-called 'Nickell bias' with a limiting distribution that does not depend on the country-specific currency crises. B-C (2005) has proven that the test also has a standard normal limiting distribution as $N \rightarrow \infty$, even if the number of time periods is fixed. However, there is no assumption of the number of time periods in the two regimes, which tend to be infinity but cross-sections are assumed to be independent.

\subsection{Critical Values}

To avoid the Nickell bias, we compute the sample CVs by means of Monte Carlo simulation following a procedure advocated by Breuer, McNown and Wallace (2002). Pesaran (2007) has shown that the linear individual CADF (Cross Augmented Dickey Fuller) and the panel statistic (cross-sectionally augmented Im, Pesaran and Shin (2003), CIPS) have non-normal distributions. To address the issue, the CVs (for different $N$ and $T$ ) are obtained by Monte Carlo simulations. Pesaran's (2007) method of estimation on the simulated CVs is based on the exact values of the parameter estimates employed in the PPP for each group of countries. We apply the formula of $\hat{b}_{i}=\left(S_{i,-1}^{r T} \bar{M} S_{i,-1}^{r}\right)^{-1}\left(S_{i,-1}^{r T} \bar{M} \Delta S_{i}^{r}\right)$ in equation (2), where $\bar{M}$ and $\bar{H}$ are as defined earlier. The $\Delta S_{i}^{r}$ can be generated from $\Delta S_{i, t}^{r}=b_{i} S_{i, t-1}^{r}+e_{i t}$ or $S_{i, t}^{r}-S_{i, t-1}^{r}=b_{i} S_{i, t-1}^{r}+e_{i t}$. Upon simplification, we have the following equation:

$$
S_{i, t}^{r}=\left(b_{i}+1\right) S_{i, t-1}^{r}+e_{i t} .
$$


Here, we generate the error series from the standard normal distributions, with the variance covariance matrix given by the early estimates obtained from Pesaran's (2007) procedure. Under the unit-root null, each simulated data point is generated from the error series by using the parameter estimates with the intercept, which was set equal to zero.

Briefly, using equation (3) and restrict $S_{i, t-1}^{r}=0$ for $i=1,2, \ldots, N, b_{i}=\hat{b}_{i}$ and $e_{i t} \sim \operatorname{iid} N(0,1)$, the value of $S_{i, 1}^{r}, S_{i, 2}^{r}, \ldots \ldots \ldots, S_{i, T}^{r}$ can be generated:

$$
\begin{aligned}
& S_{i, 1}^{r}=e_{i 1}, \\
& S_{i, 2}^{r}=\left(\hat{b}_{i}+1\right) S_{i, 1}^{r}+e_{i 2}, \\
& \vdots \\
& S_{i, T}^{r}=\left(\hat{b}_{i}+1\right) S_{i, T-1}^{r}+e_{i T},
\end{aligned}
$$

where $\hat{b}_{i}$ is the estimated coefficient for $i=1,2, \ldots, N$. The generated $S_{i, 1}^{r}, S_{i, 2}^{r}, \ldots, S_{i, T}^{r}$ are then used to estimate the parameter of the model in equation (2). To this end, the new $b_{i}$ is obtained $\left(\hat{b}_{i}^{*}\right)$. In the generated series, 50 observations are added to the true value of $T$ for each group, and these observations are then discarded in the final estimates in order to reduce the initial effects. The remaining observations that correspond exactly to the number of observations on the dependent variable are used to compute the CVs of the unit-root test at the 0.05 significance level. To minimise the possible biases induced by nuisance parameters in finite sample, the CVs are simulated and it should be mentioned that this is seldom done in past studies. In order to achieve an acceptable degree of precision, the number of replications used to simulate the CVs in the simulation exercise is set to 5,000 replications. Table 3 reports the simulated CVs based on 5,000 replications from our dataset.

\section{Data and Empirical Results}

The empirical analysis is based on monthly frequency data that span the period January 1986 to October 2009 (286 observations). The series is collected from the International Financial Statistics of the International Monetary Fund. ${ }^{6}$ Our focus is on US dollar rates because it is the trading currency for most emerging and developing Asian countries. The 14 countries selected for investigation are China (CHN), Hong Kong SAR (HKG), India (IND), Indonesia (INDO), South Korea (KOR), Malaysia (MYS), Myanmar (MMR), Pakistan (PAK), the Philippines (PHL), Samoa (WSM), Singapore (SGP), Sri Lanka (LKA), Taiwan (TWN) and Thailand (THA). The variety of exchange rate regimes adopted by these globalised developing countries provides a motivation of selecting them for further analysis in the current study. Rajan (2010, p. 2), in his assessment of the exchange rate regime in the region, concluded that "it is evident that Asia is home to a wide array of exchange rate regimes, though there are signs of gradual movement toward somewhat greater exchange rate flexibility in many of the regional countries." More recently, however, many of these Asian countries have been building up their international

6 The data for Taiwan and the consumer price index for China were compiled from Datastream. 
reserves, either to maintain their fixed exchange rates or to offset the pressure of currency appreciation in the context of a managed float.

As a first step, we carried out the standard unit-root tests on the individual series to establish whether it is legitimate to pool all the RER series in one panel. The tests (Augmented-Dickey-Fuller and Ng \& Perron, 2001) indicate that RER (not reported) has a unit-root. This is no surprise as it is in line with a large part of the existing literature that have largely failed to show long-run PPP in the univariate settings. Given these empirical results, we proceed with the panel methods to confront with the issue of low power often associated with the univariate unit-root tests by exploiting cross-section variations. The analyses based on sub-panels (full panel, Association of Southeast Asian Nations (ASEAN)-5, B-C's sample countries) allow us to find out if the test outcomes are sensitive to the selection of panel members. All - including Pesaran (2007) - but one of the test statistics from the so-called first-generation panel-based models seem to reject PPP at the indicated significance levels. The findings so far seem to be restrictive since there is a possibility that the series under investigation was influenced by the noisy and unstable observations due to currency crises.

Several methods have been developed to date currency crises. In this study, we consider three criteria as suggested by Esquivel and Larrain (1998) and B-C, to detect the currency crisis periods for all the countries under review. The first two criteria are drawn from Esquivel and Larrain (1998) while the third criterion is proposed by B-C. Following the first criterion (criterion 1, hereafter), a period is defined as a currency crisis period if the cumulative three-month RER growth rate approaches $(\geq)$ threshold level of 15 percent or more. The second criterion (criterion 2) is the most conservative definition of a currency crisis. For this criterion, a period is defined as a currency crisis when the one-month RER growth rate exceeds a threshold level of 2.54 times the specific country's standard deviation and is more than 4 percent proportionately. B-C proposed another simple criterion (criterion 3 ) to identify the currency crisis dates. A currency crisis is identified when the one-month RER growth rate exceeds a threshold level of 10 percent.

We consider all three criteria, and Table 1 collects all the dates of currency crises based on the above-mentioned criteria. The timing of currency crises varies across the three criteria, and this is no surprise given that different definitions are used to date them. In general, we observed that, of the three, criterion 2 picked up the largest number of currency episodes (extreme observations). As shown in Table 1, all three methods pick up crisis events of the 1997-1998 AFC in Thailand, Indonesia, the Philippines, Malaysia, South Korea and Sri Lanka. For Singapore, Myanmar, Pakistan, Samoa and Taiwan, the dating method based on criterion 2 identifies crisis events around the Asian crisis. Many of the Asian countries were forced to abandon their policy of pegged exchange rates after July 1997 as they went into economic recession. As noted in Lestano and Jacobs (2007), the clustering of crises around 1997-1999 is consistent with theories of speculative attack and policy responses that consider the possibility of contagion across countries. This observation is also consistent with the view of several scholars that the flexibility of the exchange rate rose sharply after the crisis subsided as pegged exchange rates in the Asian countries (including the Chinese renminbi) broke down. 
Unlike in the other Asian countries, no evidence of a currency crisis was detected in Hong Kong SAR during the AFC based on all three criteria. This is hardly surprising as Hong Kong adopted a currency board arrangement exchange rate regime; hence, it did not suffer from the regional crises compared to its neighbours because its exchange rate arrangements were more flexible. As in Hong Kong SAR, all three criteria show that the Chinese renminbi was virtually unaffected by the large currency interventions. It is worth noting that China had huge foreign exchange reserves and the renminbi was not freely convertible during that period, so it was insulated from the AFC. In addition, China managed to avoid economic difficulties associated with the contagion because much of the capital inflows into the country were foreign direct investment (FDI) and not short-term portfolio investments and debts, which is far less volatile. Nonetheless, as shown in Table 1, all the methods confirm a major shift in the renminbi in July 1986 associated with the beginning of an economic reform program and lower inflation after a round of double-digit inflation in 1985. Another important date detected is connected to the unification of China's dual exchange rates and the 1994 devaluation of the renminbi. Again, all the criteria detect sharp changes in exchange rates against the US dollar rate in January 1994.

India has also experienced its own local shocks, along with large changes in the Indian rupee. India liberalised its economy, transforming it into one of the fastest growing. As many analysts have noted, this policy change followed an acute balanceof-payments crisis in 1991. In addition, reaction to a series of bombings (political instability) in March 1993 led to wide fluctuations in the currency market. It should be mentioned that the Indian rupee was made convertible on current account in August 1994. Finally, Pakistan moved from a managed float to a freely flexible exchange rate regime in July 2000. A glance at the data reveals large movements in the Pakistan rupee before the initiation of the free floating exchange regime and loosening of capital controls. Again, suggesting that most of the Asian countries do not share common break dates and the structural breaks in some of these countries can be country-specific.

To what extent was the RER in Asian countries affected by the late 2000s global financial crisis (GFC)? Most, but not all, of the currencies were affected by the GFC including Indonesia (criteria 1 and 3), South Korea (criteria 1, 2 and 3), the Philippines, Singapore, India, Pakistan, Samoa and Taiwan (criterion 2). Interestingly, we find that Asian currencies were less severely affected by the GFC which was truly global. Despite the region's high level of integration into the global economy and the magnitude of the GFC, the Asian countries did not suffer from financial crisis. Ostry et al. (2010) found some modest evidence that controls on certain types of capital inflows for most emerging economies before the GFC were associated with reduced financial vulnerabilities during the crisis. As mentioned in Blanchard, Faruqee, \& Das (2010), the Asian countries suffer from a trade crisis instead as their major trading partners go into deep recession. These important crisis dates as well as others are listed in Table 1 . It should be mentioned that most structural break tests might not pick up the breaks at the end of the sampling period due to the trimming factor. The salient features of the data, if ignored, may have significant influence on the outcome of our results.

Next, a new set of series was generated using the segmented mean function proposed by B-C to exclude heterogeneous currency crises episodes, as discussed 
Table 1. Dating the currency crises in Asia, 1986-2009

\begin{tabular}{|c|c|c|c|}
\hline & Criterion 1 & Criterion 2 & Criterion 3 \\
\hline & $\begin{array}{l}\text { Cumulative } 3 \text {-month RER } \\
\text { growth rate } \geq \text { threshold level } \\
\text { of } 15 \% \text { or more }\end{array}$ & $\begin{array}{l}\text { 1-month RER growth rate }> \\
\text { threshold level of } 2.54 \times \text { specific } \\
\text { country's standard deviation } \\
\text { and }>4 \% \text { proportionately }\end{array}$ & $\begin{array}{l}\text { 1-month RER growth } \\
\text { rate }>\text { threshold level of } \\
10 \%\end{array}$ \\
\hline INDO & $\begin{array}{l}86: 9-86: 11 ; 97: 8-99: 2 ; 99: 6- \\
00: 1 ; 00: 9-00: 10 ; 01: 4-01: 11 \\
05: 10 ; 08: 10-09: 2 ; 09: 4\end{array}$ & $86: 9 ; 97: 12-98: 2 ; 98: 5-98: 8 ; 98: 10$ & $\begin{array}{l}86: 9 ; 97: 8 ; 97: 10 ; 97: 12- \\
98: 2 ; 98: 4-98: 8 ; 98: 10 ; \\
99: 6 ; 99: 8-99: 10 ; 01: 4 ; \\
01: 7 ; 08: 10 ; 08: 12\end{array}$ \\
\hline MYS & $97: 8-98: 4$ & $97: 8-97: 10 ; 97: 12-98: 2 ; 98: 6 ; 98: 9$ & $97: 8 ; 97: 12-98: 2$ \\
\hline $\mathrm{PHL}$ & $\begin{array}{l}86: 4 ; 92: 9-92: 10 ; 97: 9-98: 6 ; \\
00: 11-00: 12\end{array}$ & $\begin{array}{l}86: 2-86: 3 ; 90: 8 ; 90: 11 ; 92: 8-92: 9 ; \\
93: 9,97: 7 ; 97: 9 ; 97: 12 ; 98: 2-98: 4 ; \\
98: 6 ; 98: 10 ; 00: 10 ; 08: 10\end{array}$ & $86: 2 ; 97: 9 ; 97: 12 ; 00: 10$ \\
\hline SGP & $98: 2$ & $\begin{array}{l}91: 3 ; 97: 10 ; 97: 12-98: 2 ; 98: 5-98: 9 ; \\
08: 12-09: 1\end{array}$ & - \\
\hline THA & 97:7-97:10; 97:12-98:4; 99:10 & 97:7; 97:10; 97:12-98:3; 99:9 & $97: 7 ; 97: 12-98: 3$ \\
\hline HKG & - & - & - \\
\hline $\mathrm{CHN}$ & $\begin{array}{l}86: 7-86: 9 ; 89: 12-90: 2 \\
94: 1-94: 3\end{array}$ & $86: 7 ; 89: 12 ; 90: 11 ; 94: 1$ & $86: 7 ; 89: 12 ; 90: 11 ; 94: 1$ \\
\hline KOR & $\begin{array}{l}97: 11-98: 5 ; 98: 7-98: 10 \\
08: 9-09: 5\end{array}$ & $\begin{array}{l}\text { 97:11-98:1; 98:3; 98:7-98:8; } \\
08: 9 ; 08: 11-09: 3\end{array}$ & $\begin{array}{l}\text { 97:11-98:1; 98:3; 98:7; } \\
08: 9 ; 08: 11-08: 12 ; \\
09: 2-09: 3\end{array}$ \\
\hline IND & $91: 7-91: 9 ; 93: 3-93: 5$ & $\begin{array}{l}91: 7 ; 93: 3 ; 95: 9 ; 96: 1 ; 97: 11 ; \\
07: 4 ; 08: 5 ; 08: 9 ; 09: 5\end{array}$ & $91: 7 ; 93: 3$ \\
\hline MMR & $\begin{array}{l}86: 12-87: 1 ; 89: 8-89: 10 ; 90: 9 ; \\
93: 4-93: 5 ; 97: 8-97: 9 ; 98: 6- \\
98: 7 ; 01: 8-01: 9 ; 02: 5-02: 8\end{array}$ & $\begin{array}{l}86: 7 ; 86: 11-86: 12 ; 87: 3 ; 87: 8- \\
87: 9 ; 88: 8 ; 89: 4 ; 89: 7-89: 9 ; \\
90: 7-90: 8 ; 91: 3 ; 91: 5 ; 91: 12 ; \\
92: 6 ; 92: 8 ; 92: 10 ; 93: 3 ; 95: 8 ; \\
97: 1 ; 97: 7-97: 8 ; 98: 5-98: 6 ; \\
98: 12 ; 00: 10 ; 01: 6 ; 01: 8 ; 02: 4- \\
02: 6 ; 02: 8-02: 9 ; 03: 4 ; 06: 11\end{array}$ & $93: 3 ; 00: 9$ \\
\hline PAK & $00: 10$ & $\begin{array}{l}86: 5 ; 89: 5 ; 93: 7 ; 95: 10 ; \\
96: 10 ; 97: 10 ; 98: 6 ; 99: 5 ; 00: 9 \\
01: 10 ; 08: 11\end{array}$ & $99: 5 ; 00: 9$ \\
\hline WSM & $\begin{array}{l}88: 6-88: 8 ; 94: 2-94: 3 ; 01: 9 \\
04: 1-04: 3\end{array}$ & $\begin{array}{l}88: 6-88: 8 ; 91: 7 ; 92: 1 ; 94: 1-94: 2 \\
98: 8 ; 00: 9-00: 10 ; 01: 7 ; 01: 9 ; 02: 5 ; \\
02: 8 ; 02: 12 ; 03: 4-03: 5 ; 04: 1 ; 06: 3 \\
08: 10 ; 08: 12-09: 1 ; 09: 5\end{array}$ & $88: 6 ; 04: 1$ \\
\hline LAK & $98: 5-98: 9 ; 01: 3$ & $98: 5 ; 98: 7$ & $98: 5 ; 98: 7$ \\
\hline TWN & - & $\begin{array}{l}87: 3 ; 87: 8 ; 89: 5 ; 89: 11 ; 97: 10- \\
97: 11 ; 98: 10 ; 09: 2\end{array}$ & - \\
\hline
\end{tabular}

Notes: $\mathrm{INDO}=$ Indonesia, $\mathrm{MYS}=$ Malaysia, $\mathrm{PHL}=$ the Philippines, SGP = Singapore, $\mathrm{THA}=$ Thailand, HKG = Hong Kong SAR, CHN = China, $\mathrm{KOR}=$ South Korea, IND = India, MMR = Myanmar, PAK = Pakistan, WSM $=$ Samoa, LKA $=$ Sri Lanka, TWN = Taiwan, and RER = real exchange rate. The currency crisis dates are detected based on three criteria which were proposed by Esquivel and Larrain (1998) for criterion 1 and criterion 2 while criterion 3 is based on Breitung \& Candelon (2005). 
in the previous section. The lag length for the tests is chosen based on the model selection criteria and Lagrange Multiplier (LM) serial correlation tests. To gain power, we pool the countries in several sub-panels as mentioned earlier and applied the B-C panel unit-root test. The test statistics for the full panel failed to reject the unit-root null based on all three criteria of dating the crises. Taylor and Sarno (1998) argued that if the univariate unit-root tests applied to a set of RERs lead to the rejection of the unit-root null for one or more of the series, then the results from the traditional panel unit-root test applied to the same series are 'completely uninformative. ${ }^{7}$ To overcome this limitation associated with the panel unit-root tests, we exclude Thailand and Indonesia, which are stationary at univariate setting from the analysis. The results for all the sub-panels, including the analysis discarding the stationary mean-reverting series on the PPP are rather mixed, with results from the full panel favouring the null unit-root hypothesis. As mentioned earlier, the $C D$ in the data may bias the empirical results, and therefore the results presented above must be interpreted with caution. O'Connell (1998) showed that ignoring CD severely distorts the size of the panel unitroot tests, especially when $\mathrm{n}$ (panel members) is large (Banerjee, Marcellino, \& Osbat, 2004; Pesaran, 2007). The conclusion is not safe and we should consider the crosssectionally augmented Im, Pesaran and Shin (2003) (CIPS) tests if cross dependence is presented. For detail discussion as well as practical application of the CIPS test, see also Pesaran (2007).

LM of Breusch and Pagan's (1980, CD Im ) and Pesaran CD (PCD) tests are deployed in our study to test for CD. We first compute pairwise cross-sectional correlation coefficients of the residuals from equation (4), together with the associated PCD test statistics. Row 1 (Table 2) shows the sample pairwise correlations of the residuals for all criteria. All in all, the results may be summarised as follows: First, the cross-correlation residuals reported in Table 2 are much lower compared with data that do not account for currency crisis periods (not shown in Table 2). Second, there is a sharp drop in the $C D$ based on criterion 2. Both of the $C D$ tests overwhelmingly reject the null of no $C D$ in favour of the alternative, that is, there is evidence to indicate that at least one crosssectional is dependence at the 5 percent significance level for all three criteria. Based on the statistical evidence of $C D$ in the RERs, we caution readers about the earlier findings from the first-generation, including the B-C panel unit-root test. ${ }^{8}$ Specifically, two points are worth mentioning. First, there is little gain in the precision of the panelbased approach compared to the single equation ordinary least squares when the CD is present. Second, it also indicates that the commonly used panel unit-root tests are no longer asymptotically similar. As a further step, we extend B-C panel unit-root test by employing a procedure considering both currency crises and CD simultaneously. Briefly, we make some modifications to the B-C procedure by employing the Pesaran's (2007) common factor $\left(f_{t}\right)$ as a proxy to filter the $C D$.

7 The univariate tests (that excludes data during currency crisis periods) indicate that the unit-root null cannot be rejected in all but two countries - Indonesia and Thailand. For Indonesia, the RER series is found to be stationary based on criteria 1 and 3, while for Thailand, all criteria point to the stationarity of the RER. In order to conserve space, the results can be requested from authors.

8 We consider this as our contribution to the literature since the paper by B-C focusses mainly on breaks but did not address the CD issue that may bias the empirical findings. 
Table 2. Cross dependency (CD) tests (without outliers)

\begin{tabular}{|c|c|c|c|c|}
\hline & Criterion 1 & \multicolumn{2}{|c|}{ Criterion 2} & Criterion 3 \\
\hline$\left|\hat{\rho}_{i j}\right|$ & 0.142 & \multicolumn{2}{|c|}{0.116} & 0.125 \\
\hline$C D_{l m}$ & $977.136^{\mathrm{a}}$ & \multicolumn{2}{|c|}{$617.643^{\mathrm{a}}$} & $773.061^{\mathrm{a}}$ \\
\hline PCD & $19.330^{\mathrm{a}}$ & \multicolumn{2}{|c|}{$15.746^{\mathrm{a}}$} & $17.528^{\mathrm{a}}$ \\
\hline \multirow{2}{*}{\multicolumn{5}{|c|}{$\begin{array}{l}\text { Notes: }{ }^{a} \text { Denotes significance at the } 5 \% \text { significance level based on its corresponding critical values (CVs). } \mid \hat{\rho}_{i j} \\
\text { denotes the sample pairwise correlations of the residuals denoted as } \hat{\rho}_{i j}=\hat{\rho}_{j j}=\sum_{t=1}^{T} \hat{e}_{i t} \hat{e}_{j t} /\left(\sum_{t=1}^{T} \hat{e}_{i t}^{2}\right)^{1 / 2}\left(\sum_{t=1}^{T} \hat{e}_{j t}^{2}\right)^{1 / 2} \\
\text { Reject } \mathrm{H}_{0} \text { when the test statistic } C D_{l m}=T \sum_{i=1}^{N-1} \sum_{j=i+1}^{N} \hat{\rho}_{i j}>\chi_{(N(N-1) / 2)}^{2} \text { and } P C D=\sqrt{2 T / N(N-1)} \sum_{i=1}^{N-1} \sum_{j=i+1}^{N} \hat{\rho}_{i} \\
>\mathrm{N}(0,1)=1.96 \text { at the } 5 \% \text { level. }\end{array}$}} \\
\hline & & & & \\
\hline \multicolumn{5}{|c|}{ Table 3. Panel unit-root test robust to currency crises and cross-sectional dependence } \\
\hline & & Criterion 1 & Criterion 2 & Criterion 3 \\
\hline \multirow[t]{2}{*}{ 14-Asian } & test statistics & $-0.0773^{a}$ & $0.3079^{a}$ & $-0.2099^{a}$ \\
\hline & CVs & 4.1130 & 4.0528 & 4.0354 \\
\hline \multirow[t]{2}{*}{ ASEAN-5 } & test statistics & $-0.1144^{a}$ & $0.9765^{a}$ & $-1.4158^{a}$ \\
\hline & CVs & 4.0126 & 4.0164 & 4.0346 \\
\hline
\end{tabular}

Notes: a Denotes significance at $5 \%$ significance level along with its critical values (CVs). The CVs are computed based on 5,000 replications at the $5 \%$ significance level.

Interestingly, the test statistics (Table 3$)$ for the full panel $(n=14)$ are found to be significant at the 5 percent significance level or better for all three criteria. As a robustness check, we rerun the test for the ASEAN-5 countries. The RERs are found to be mean-reverting and invariant to the three definitions (classifications) of the currency crises, that is, a similar qualitative pattern emerges in all three definition episodes, replicating $\mathrm{B}-\mathrm{C}$ major findings although our sample includes the observation from recent GFC. We find no evidence to indicate that PPP tends to work better empirically under a more flexible exchange rate regime. Being linked to the US dollar prior to the Asian crisis and to a more flexible exchange rate in the post-crisis period seems to be associated with no clear-cut difference in the behaviour of the RER. ${ }^{9}$

To confirm that our estimated model is free from outliers, we present the box plots of the estimated residuals obtained from our new procedure in Figure 1 . All in all, the mean of estimated residuals for each country is close to zero, with a smaller spread $\left(\sigma_{i}\right)$, except for the case of Indonesia and South Korea. By assuming that $\sigma_{i} \sim 1$ for $i=1,2, \ldots$, $\mathrm{N}$, the values, however, are still in the range of \pm 3 . This confirms that after removing observations associated with the currency crisis, the data applied in the empirical analysis is free from extreme observations and that our results validate PPP as longrun hypothesis. In other words, PPP puzzle does not hold for the Asian countries under review (including China).

9 Non-rejection of the test in this paper implies PPP tends to hold for at least one country in the panel. A modification of the test based on the panel stationarity test may be well suited for this limitation. 


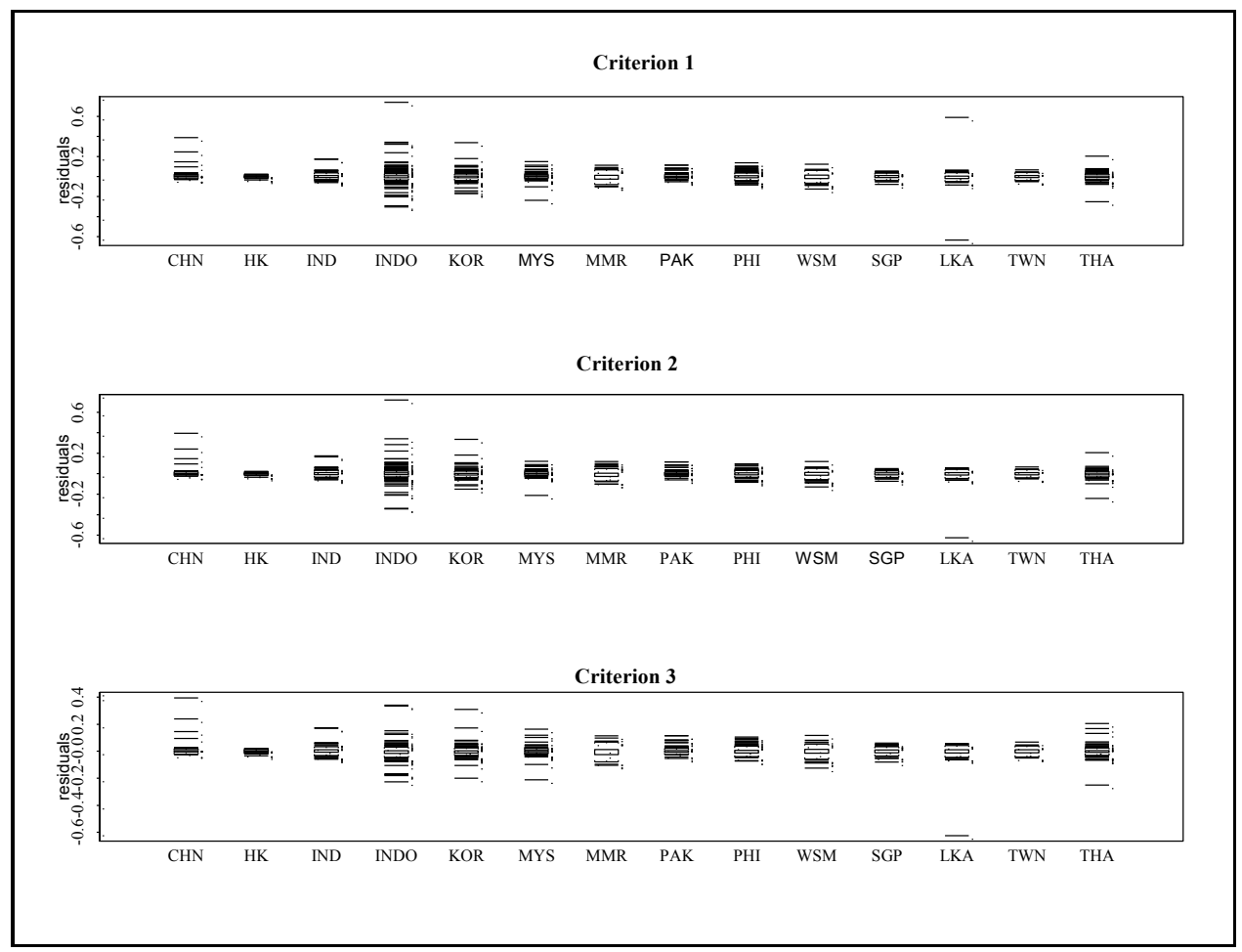

Figure 1. Box plot of the fitted residuals

At this point, it is important to ask the question: How do the results differ from those in the existing literature? First, from the methodological perspective, Aloy, Boutahar, Gente and Péguin-Feissolle (2011) forcefully argued that there is no one-sizefits-all model to resolve the PPP puzzle. Their results, based on a sample of 78 countries (including most of the countries under review), reveal that only a few countries fit longmemory mean-reverting models and nonlinear models. It is worth noting here that nonlinear unit-root tests and estimation of a long-memory process may be biased in the presence of structural or regime changes based on the usual estimation methods (Villavicencio, 2008). Contrary to the results in recent literature, we show that PPP is upheld using the linear specification, but only after accounting the noisy observations. As currency crisis does not affect permanently the link between exchange rate and relative prices, PPP long-run equilibrium is a useful benchmark when assessing an exchange rate misalignment. A recent addition to the literature on the subject (e.g., Maican \& Sweeney, 2013; Baharumshah et al., 2015) appears to support our view. ${ }^{10}$

10 Maican and Sweeney (2013) who considered several specifications found that the linear model is superior to the nonlinear specification and may help to explain the PPP puzzle. Our work seems to support their view in the sense that the PPP puzzle is not an issue in the countries under review; see Baharumshah et al. (2015). In most of the Asian countries, large swings occurred in currency markets during the AFC. Baharumshah et al. (2015) argued that the deviations from PPP are large during that period, but decline afterward. Hence, supporting the idea deviations from PPP are temporary. 
Applying the same tests as in B-C, but with sample extended to recent GFC, we find that PPP holds outside the crisis periods. This is in line with the SGMs, which stress the importance of non-fundamentals (self-fulfilling prophecies or contagion) during a speculative attack. Baharumshah et al. (2015) have highlighted that the AFC has not altered the speed of the PPP adjustments. However, our finding is at odds with Ozdemir and Cakan (2010) who found the speed of convergence via the US dollar is much faster for the post-crisis period. For the former, they base their half-life estimates - the number of months it takes for the deviations to subside permanently below $50 \%$ in response to a unit shock - on the local-persistent model. Second, Drine and Rault (2008) have claimed that the behaviour of the RERs is closely linked to the exchange rate regime. The argument is that mean reversion, a necessary condition for long-run PPP to hold, is most rapid when nominal exchange rates are officially pegged and that exchange rates, rather than prices, do most of the adjustment. In contrast to those studies, we find that the outcome is irrelevant to the exchange rate arrangement; PPP holds in a currency board arrangement, as in the case of Hong Kong SAR, or a managed float, as in the case of Malaysia. ${ }^{11}$ It is often claimed that the Asian currencies have been closely tied with the Japanese yen due to the active interaction of Japan with the emerging Asian economies (since the 1990s) while the US dollar appears to have declined in importance in the post-Asian crisis (e.g. Aggarwal et al., 2000). Contrary to this yen block argument, our results confirm that the US dollar has not lost its dominance throughout the region. Kim, Min, Hwang and McDonald (2009, p. 163), in reviewing the AFC, concluded that "the Asian crisis was not caused by these countries' current-account deficits, as their current accounts were on sustainable paths." Thus, our finding in favour of mean reversion in the RER of the Asian-US dollar rates appears to support the view that the AFC and the GFC are not adequately explained by the FGMs - i.e. not fundamentally driven. Additionally, Husted and MacDonald (1999) have shown that the monetary approach to the exchange rate model does a good job in replicating the actual exchange rate movement in the Asian countries over 1974-1996. Based on the Asian/yen exchange rates, they confirmed that the predictions from the exchange rate model (except for Malaysia) were very close to the actual value prior to the AFC. Like B-C, they concluded that the AFC cannot be due to the traditional fundamentals. The AFC fits more to the second-generation type of crises. It seems that it is difficult to uncover early warning indicators from our dataset. Moreover, Choi and Park (2008) found that interest rates are generally ineffective in stabilising exchange rates.

\section{Conclusion}

This paper investigates the currency episodes from the viewpoint of the validity of the PPP hypothesis by applying Pesaran's (2007) panel unit-root test that allows for crosssectional dependencies. We find that PPP provides a good description of the RERs in our sample of Asian countries, but this is the case only when the data from the crisis

11 According to a recent IMF classification of exchange rate arrangements, seven of the sample countries operate under floating exchange rates except China, Singapore and Indonesia (crawling-like arrangement), Samoa (conventional peg arrangement), Hong Kong SAR (currency board arrangement), and Malaysia and Myanmar (managed arrangement). 
episodes (both outliers and structural breaks) are accommodated in the analysis. We identified several currency episodes of the past two decades are responsible for the breakdown of PPP in the region. Although China, India and Pakistan did not experience the same crisis episodes as the other Asian countries, these countries were severely affected by local shocks from their own crises. This also explains why a continuous assessment of the parity condition is necessary as it is affected by the economic and financial environments. Using more recent data, we find that our results collaborate with those reported earlier in Nusair (2001), Hooi and Smyth (2007) and Zurbruegg and Allsopp (2004); they found PPP holds for most of the Asian countries when breaks are adequately accounted for the country they studied. We confirmed that the time series properties of RER during the post-crisis periods are not significantly different from those in the pre-crisis periods - they exhibit $I(0)$ process. Therefore, we find no notable differences between the two crises in the recent decades. The crises cannot be predicted based on the fundamental based exchange rate model. Several scholars have emphasised currency crises - exchange rate depreciating substantially during a short period of time - can occur even if no secular trend or movements in economic fundamentals (e.g., fiscal deficits and monetary growth) can be identified. This also explains why early warning models were unsuccessful in forecasting future crises.

From a statistical viewpoint, testing the long-run PPP hypothesis during crisis periods can be problematic if these noisy and unstable observations - currency crises or large currency interventions - are not properly accounted for in the empirical analysis. Our results also highlight that the exchange rate regime does not influence the behaviour of the US dollar-based series. We noted that the sample of Asian countries has adopted heterogeneously de facto exchange rate regimes. The significance of our findings is that shocks (including the currency crisis) or institutional changes that follow after that have no lasting impact on the Asian RERs in the past three decades. Evidence of linear mean reversion in RER is only observed when shocks are unaccounted for in the empirical model. The deviations from PPP due to currency crisis are only temporary and hence should not have an adverse effect on their long-term competitiveness or trade with their major trading partners. Together, these findings may partially explain the high growth performance observed in these countries over the past decades.

\section{References}

Aggarwal, R., Montanes, A., \& Ponz, M. (2000). Evidence of long-run purchasing power parity: Analysis of real Asian exchange rates in terms of the Japanese yen. Japan and the World Economy, 12(4), 351-361.

Aloy, M., Boutahar, M., Gente, K., \& Péguin-Feissolle, A. (2011). Purchasing power parity and the long memory properties of real exchange rates: Does one size fit all? Economic Modelling, 28(3), 1279-1290.

Baharumshah, A.Z., Liew, V.K.-S., \& Chowdhury, I. (2010). Asymmetry dynamics in real exchange rates: New results on East Asian currencies. International Review of Economics and Finance, 19(4), 648-661.

Baharumshah, A.Z., Soon, S.-V., \& Boršič, D. (2013). Real interest parity (RIP) in Central and Eastern European countries: Evidence on integration into EU and the US markets. Journal of International Financial Markets, Institutions and Money, 25(July), 163-180. 
Baharumshah, A.Z., Soon, S.-V., \& Wohar, M.E. (2015). Parity reversion in the Asian real exchange rates: New evidence from the local-persistent model. Applied Economics, 47(59), 63956408.

Bahmani-Oskooee, M., Kutan, A.M., \& Zhou, S. (2008). Do real exchange rate follows a nonlinear mean reverting process in developing countries? Southern Economic Journal, 74(4), 10491062.

Bahmani-Oskooee, M., \& Hegerty, S.W. (2009). Purchasing power parity in less-developed and transition economies: A review paper. Journal of Economic Surveys, 23(4), 617-658.

Bahmani-Oskooee, M., Chang, T., \& Wu, T. (2014). Revisiting purchasing power parity in African countries: Panel stationary test with sharp and smooth breaks. Applied Financial Economics, 24(22), 1429-1438.

Bai, J., \& Perron, P. (2003). Computation and analysis of multiple structural change models. Journal of Applied Econometrics, 18(1), 1-22.

Banerjee, A., Marcellino, M., \& Osbat, C. (2004). Some cautions on the use of panel methods for integrated series of macroeconomic data. The Econometrics Journal, 7(2), 322-340.

Blanchard, O.J., Faruqee, H., \& Das, M. (2010). The initial impact of the crisis on emerging market countries. Brookings Paper on Economic Activity, 41(1), 263-323.

Breitung, J., \& Candelon, B. (2005). Purchasing power parity during currency crises: A panel unit root test under structural breaks. Review of World Economics, 141(1), 124-140.

Breuer, J.B., McNown, R., \& Wallace, M.S. (2002). Series-specific unit root tests with panel data. Oxford Bulletin of Economics and Statistics, 64(5), 527-546.

Breusch, T.S., \& Pagan, A.R. (1980). The Lagrange Multiplier test and its applications to model specification in econometrics. Review of Economic Studies, 47(1), 239-253.

Chang, H.-L., Liu, D.-C., \& Su, C.-W. (2012). Purchasing power parity with flexible Fourier stationary test for Central and Eastern European countries. Applied Economics, 44(32), 4249-4256.

Choi, I., \& Park, D. (2008). Causal relation between interest rate and exchange rates in the Asian currency. Japan and the World Economy, 20(3), 435-452.

Corsetti, G., Pesenti, P., \& Roubini, N. (1999). What caused the Asian currency and financial crisis? Japan and the World Economy, 11(3), 305-373.

Dooley, M.P. (1999). Origins of the crisis in Asia. In W.C. Hunter, G.G. Kaufman, \& T.H. Krueger (Eds.), The Asian financial crisis: Origins, implications and solutions. Boston: Kluwer Academic Publishers.

Drine, I., \& Rault, C. (2008). Purchasing power parity for developing and developed countries: What can we learn from non-stationary panel data models? Journal of Economic Surveys, 22(4), 752-773.

Enders, W., \& Lee, J. (2012). A unit root test using a Fourier series to approximate smooth breaks. Oxford Bulletin of Economics and Statistics, 74(4), 574-599.

Esquivel, G., \& Larrain, F.B. (1998). Explaining currency crises (Harvard Institute for International Development (HIID) Development Discussion Paper No. 666). Cambridge, MA: University of Harvard.

Flood, R.P., \& Marion, N.P. (1997). Policy implications of 'second-generation' crisis models. International Monetary Fund (IMF) Staff Papers 44(3), 383-390.

Fontaine, T. (2005). Currency crises in developed and emerging market economies: A comparative empirical treatment (International Monetary Fund (IMF) Working Paper No. WP/05/13). Washington DC: International Monetary Fund.

Hooi, L.H., \& Smyth, R. (2007). Are Asian real exchange rate mean reverting? Evidence from univariate and panel LM unit root tests with one and two structural breaks. Applied Economics, 39(16), 2109-2120.

Husted, S., \& MacDonald, R. (1999). The Asian currency crash: Were badly driven fundamentals to be blame? Journal of Asian Economics, 10(4), 537-550. 
Im, K., Pesaran, H., \& Shin, Y. (2003), Testing for unit roots in heterogeneous panels, Journal of Econometrics, 115(1), 53-74.

International Monetary Fund. (various years). International Financial Statistics. Washington DC: Author.

Jiang, C., Bahmani-Oskooee, M., \& Chang, T. (2015). Revisiting purchasing power parity in OECD. Applied Economics, 47(40), 4323-4334.

Kim, B.-H., Min, H.-G., Hwang, Y.-S., \& McDonald, J.A. (2009). Are Asian countries' current accounts sustainable? Deficits, even when associated with high investment, are not costless. Journal of Policy Modeling, 31(2), 163-179.

Krugman, P.R. (1979). A model of balance-of-payments crises. Journal of Money, Credit, and Banking, 11(3), 311-325.

Lestano, \& Jacobs, J.P.A.M. (2007). Dating currency crises with ad hoc and extreme value-based thresholds: East Asia 1970-2002. International Journal of Finance and Economics, 12(4), 371388.

Liew, V. K.-S., Baharumshah, A.Z., \& Chong, T. T.-L. (2004). Are Asian real exchange rates stationary? Economics Letters, 83(3), 313-316.

Maican, F.G., \& Sweeney, R.J. (2013). Real exchange rate adjustment in European transition countries. Journal of Banking and Finance, 37(3), 907-926.

Matsuki, T., \& Sugimoto, K. (2013). Stationarity of Asian real exchange rates: An empirical application of multiple testing to nonstationary panels with a structural break. Economic Modelling, 34(August), 52-58.

Mishra, R.K., \& Sharma, C. (2011). An empirical test of purchasing power parity in the postBretton Woods era: A panel data approach. International Journal of Monetary Economics and Finance, 4(1), 95-109.

Montãnés, A., Olloqui, I., \& Calvo, E. (2005). Selecting of the break in the Perron-type tests. Journal of Econometrics, 129(1-2), 41-64.

$\mathrm{Ng}, \mathrm{S}$., \& Perron, P. (2001). Lag length selection and the construction of unit root tests with good size and power. Econometrica, 69(6), 1519-1554.

Narayan, P.K., \& Popp, S. (2010). A new unit root test with two structural breaks in level and slope at unknown time. Journal of Applied Statistics, 37(9), 1425-1438.

Nusair, S.A. (2001). Testing for PPP in developing countries using confirmatory analysis and different base countries: An application to Asian countries. International Economic Journal, $18(4), 467-489$.

Nusair, S.A. (2008). Purchasing power parity under regime shifts: An application to Asian countries. Asian Economic Journal, 22(3), 241-266.

O'Connell, P.G.J. (1998). The overvaluation of purchasing power parity. Journal of International Economics, 44(1), 1-19.

Obstfeld, M. (1986). Rational and self-fulfilling balance-of-payments crises. American Economic Review, 76(1), 72-81.

Ostry, J.D., Ghosh, A.R., Habermeier, K., Chamon, M., Qureshi, M.S., \& Reinhardt, D.B.S. (2010). Capital inflows: The role of controls (International Monetary Fund (IMF) Staff Position Note 10/04). Washington: International Monetary Fund.

Ozdemir, Z.A., \& Cakan, E. (2010). The persistence in real exchange rate: Evidence from East Asian countries. Economic Modelling, 27, 891-95.

Pesaran, M.H. (2004). General diagnostic tests for cross section dependence in panels (Cambridge Working Papers in Economics No. 0435). England: University of Cambridge.

Pesaran, M.H. (2007). A simple panel unit root test in the presence of cross-section dependence. Journal of Applied Econometrics, 22(2), 265-312.

Radelet, S., \& Sachs, J. (1998). The East Asian financial crisis: Diagnosis, remedies and prospects. In W.C. Brainard \& G.L. Perry (Eds.), Brookings Papers on Economic Activity. Washington, DC: Brookings Institution Press. 
Rajan, R.S. (2010). The evolution and impact of Asian exchange rate regimes (Asian Development Bank (ADB) Economics Working Paper Series No. 208, pp. 1-41). Manila, Philippines: Asian Development Bank.

Taylor, M.P., \& Sarno, L. (1998). The behaviour of real exchange rates during the post-Bretton Woods period. Journal of International Economics, 46(2), 281-312.

Taylor, M.P., Peel, D.A., \& Sarno, L. (2001). Nonlinear mean-reversion in real exchange rates: Toward a solution to the purchasing power parity puzzles. International Economic Review, 42(4), 1015-1042.

Villavicencio, A.L. (2008). Nonlinearities or outliers in real exchange rates? Economic Modelling, 25(4), 714-730.

Wu, J.-L., Tsai, L.-J., \& Chen, S.-L. (2004). Are real exchange rates non-staionary? The Pacific Basin perspective. Journal of Asian Economics, 15(2), 425-438.

Zhou, S., \& Kutan, A.M. (2011). Is the evidence for PPP reliable? A sustainability examination of the stationarity of real exchange rates. Journal of Banking and Finance, 35(9), 2479-2490.

Zurbruegg, R., \& Allsopp, L. (2004). Purchasing power parity and the impact of the East Asian currency crisis. Journal of Asian Economics, 15(4), 739-758. 
